\title{
ABM Clinical Protocol \#17: Guidelines for Breastfeeding Infants with Cleft Lip, Cleft Palate, or Cleft Lip and Palate-Revised 2019
}

\author{
Jessica O. Boyce, ${ }^{1,2,{ }^{*}}$ Sheena Reilly, ${ }^{2,3,{ }^{*}}$ Jemma Skeat, ${ }^{1}$ Petrea Cahir, ${ }^{4}$ \\ and the Academy of Breastfeeding Medicine
}

\begin{abstract}
A central goal of the Academy of Breastfeeding Medicine is the development of clinical protocols for managing common medical problems that may impact breastfeeding success. These protocols serve only as guidelines for the care of breastfeeding mothers and infants and do not delineate an exclusive course of treatment or serve as standards of medical care. Variations in treatment may be appropriate according to the needs of an individual patient.
\end{abstract}

\section{Background}

W HEN A CLEFT LIP (CL) occurs, the lip is not contiguous, and when a cleft palate $(\mathrm{CP})$ occurs, there is communication between the oral and nasal cavities (see Fig. 1 for a completely formed lip and palate). ${ }^{1} \mathrm{CL}$ may involve the lip only; lip and alveolus; or lip, alveolus, and a notch in the hard palate. The notch in the hard palate may extend all the way to the incisive foramen (Fig. 2). ${ }^{2}$ Similarly, a CP may involve only the uvula (e.g., bifid uvula), the uvula and soft palate, or extend through both the hard and soft palates (Fig. 3). ${ }^{1}$ In a complete cleft of hard and soft palates, there is no bone or muscle separating the oral and nasal cavities. A CP may be submucosal and not immediately detected intraorally if there are subtle or no corresponding clinical signs or symptoms. ${ }^{1}$ Therefore, it is essential that health professionals check for palatal clefting (both overt and submucosal) on initial presentation, by visually inspecting and palpating the palate. This should be done using a tongue depressor and flashlight to allow for inspection of the entire palate, including the uvula. An oral examination is of relevance if an infant is presenting with feeding difficulties or not gaining weight.

Surgical cleft repairs can involve multiple procedures, depending on the nature and extension of the cleft (i.e., unilateral CL versus bilateral cleft lip and palate [CLP]). The primary repair(s) are generally completed within 18 months of life, with the lip being repaired before the palate at 3-9 months of age.

\section{Incidence}

The worldwide prevalence of CL and/or CP (CL/P) ranges from 0.8 to 2.7 cases per 1,000 live births. ${ }^{5,6}$ There are differ- ences in incidence rates across racial groups and geographical locations, with the lowest reported incidence among populations of African $(\sim 0.5 / 1,000)^{6-8}$ and European descent $(\sim 1 /$ $1,000$ births $)^{5}$ and higher incidence among Native American ( 3.5/1,000) and Asian $(\sim 1.7 / 1,000)$ populations. ${ }^{6,7}$

Although reports vary considerably, it is estimated that out of the total number of infants with CL/P, $~ 50 \%$ have combined cleft lip and palate (CLP) (Fig. 4), 30\% have isolated $\mathrm{CP}$, and $20 \%$ have isolated CL; CL extending to include the alveolus occurs in $\sim 5 \%$ of cases. ${ }^{9}$ Clefts are more commonly unilateral, but can also occur bilaterally. ${ }^{10}$ Approximately $30 \%$ of cases are part of identified syndromes or multiple congenital anomaly disorders, such as 22q11 deletion syndrome, Van der Woude syndrome, or Pierre Robin sequence. ${ }^{6,7}$ The remaining $70 \%$ are nonsyndromic and occur in isolation of identified syndromes. ${ }^{6,7}$

\section{Breastfeeding and CL/P}

In these guidelines, breastfeeding refers to direct placement of the infant to the breast for feeding, and breast milk feeding refers to delivery of breast milk to the infant through bottle, cup, spoon, or any other means except the breast. Babies use suction to breastfeed successfully. The ability to generate suction is necessary for attachment to the breast, maintenance of a stable feeding position, and, together with the let-down reflex, milk extraction. Normally, when babies are feeding, their lips flange firmly against the areola, sealing the oral cavity anteriorly. The soft palate rises up to contact the pharyngeal walls and seal the oral cavity posteriorly. As the tongue and jaw drop during sucking, the oral cavity increases in

\footnotetext{
${ }^{1}$ Department of Audiology and Speech Pathology, The University of Melbourne, Melbourne, Australia.

${ }^{2}$ Speech and Language Group, Murdoch Children's Research Institute, Melbourne, Australia.

${ }^{3}$ Menzies Health Institute Queensland, Griffith University, Southport, Australia.

${ }^{4}$.Intergenerational Health, Murdoch Children's Research Institute, Parkville, Victoria, Australia.

*Joint first authors.
} 


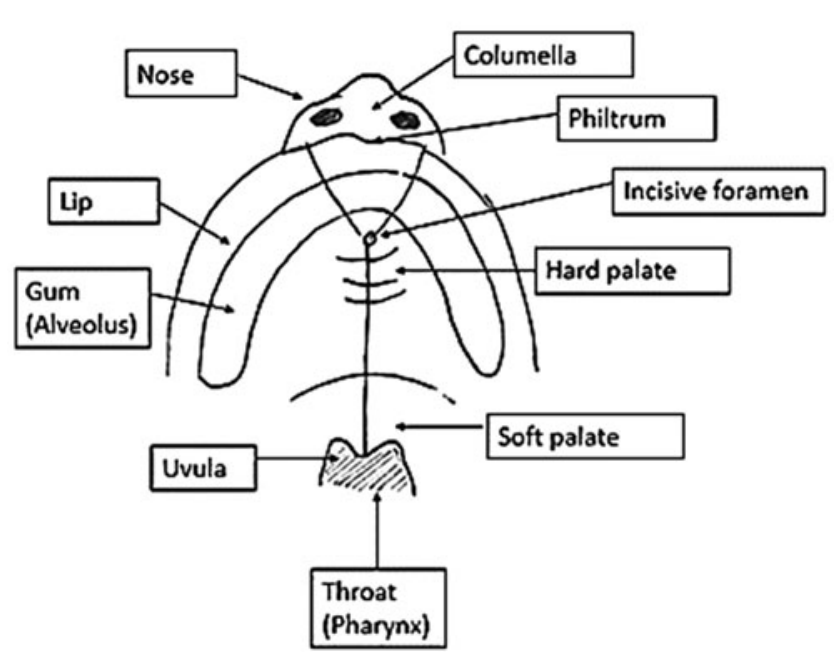

FIG. 1. Completely formed lip and palate (no cleft). This illustration shows an intact inferior view of the nose, upper lip, and hard and soft palates. Note the y-shaped suture lines where the lip, alveolus, and palate fused during gestation. During gestation, the suture lines fuse from the incisive foramen toward the philtrum area of the lip (just below the nose) and from the incisive foramen toward the uvula. A cleft of the lip and/or palate occurs when this fusion is incomplete or does not occur. (Illustration courtesy of Aiden Farrow, copyright 2018).

size, and negative pressure is generated, drawing milk from the breast. ${ }^{11}$ Suction and wave-like movement of the tongue help milk transfer and delivery during breastfeeding. ${ }^{11-13}$

There is a relationship between the size and type of cleft, maturity of the infant, and amount of oral pressure generated during feeding. ${ }^{13}$ Younger infants with larger clefts can be expected to generate less oral pressure. Most infants with isolated CL are often able to successfully breastfeed because they can generate suction and negative pressure. This is achieved when the nipple is compressed between the tongue and maxilla leading to milk being expelled into the oral cavity. ${ }^{14}$ Some infants with small soft palate clefts can generate adequate negative pressure, but others with larger soft and/or hard palate clefts may not. ${ }^{15,16}$ In addition, term and preterm newborns may generate lower suction pressure than older infants. ${ }^{17,18}$ In general, infants with CP or CLP have difficulty creating suction and negative pressure because the oral cavity cannot be adequately separated from the nasal cavity during feeding. ${ }^{19,20}$ For these infants, negative consequences may include fatigue during breastfeeding, prolonged feeding times, nasal regurgitation, reflux, insufficient milk transfer, and impaired growth and nutrition. ${ }^{21,22}$
The literature describing breastfeeding outcomes in infants with CL/P is limited. Available evidence is anecdotal and sometimes contradictory, making it challenging to develop appropriate recommendations. ${ }^{23}$ Recommendations are outlined below, and answers to frequently asked questions are detailed in Appendix A1.

\section{Recommendations}

Quality of evidence for each recommendation is noted in parentheses. Levels of evidence are listed as 1-5, with level 1 being the highest, as defined in the Oxford Centre for Evidence-Based Medicine 2011 Levels of Evidence. ${ }^{24}$

\section{Recommendations for clinical practice}

Based on the reviewed evidence, the following recommendations are made:

A. Encourage parents to breastfeed and provide breast milk when possible

1. Parents should be educated about the protective benefits of breast milk. Evidence suggests that breastfeeding protects against acute otitis media, which is highly prevalent in this population ${ }^{25-27}$ (level 2). Breast milk feeding has also been shown to have long-term health and developmental benefits above that of artificial breast milk substitutes for both infants and their breastfeeding parents. ${ }^{28-30}$ Breast milk feeding (through cup, spoon, bottle, syringe, etc.) should be promoted in preference to artificial breast milk substitutes if breastfeeding is not possible. ${ }^{21}$ Bottles that facilitate milk flow may be necessary for short- or long-term use if compensatory techniques are not sufficient for growth. These bottles may have specially designed teats, be squeezable, or use one-way valves to control milk flow. There are various brands available. Parents should be provided with anticipatory guidance regarding effective techniques for milk expression, alongside the quantity of milk needed and storage methods. ${ }^{31,32}$

2. Parents of infants with $\mathrm{CL} / \mathrm{P}$ should be advised of expected feeding outcomes based on the infant's cleft type and what has been documented in the available literature. $^{31,33}$ This guidance should be provided during the antenatal and postnatal periods. ${ }^{34}$ Consistent and expert counseling should be provided by health professionals with clinical expertise in feeding infants with CL/P $\mathrm{P}^{31,33-35}$ (levels 4 and 5).
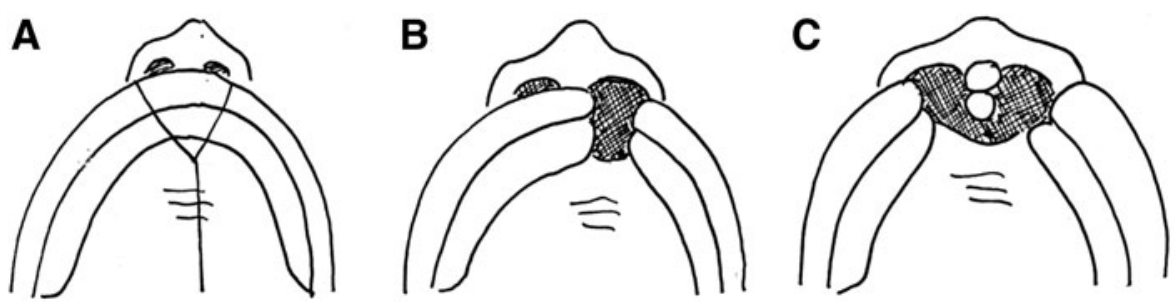

FIG. 2. Clefts of the lip. This figure illustrates (A) completely formed lip and palate (no cleft), (B) unilateral CL and (C) bilateral CL. The CLs in (B) and (C) involve the lip, alveolus, and a small notch in the hard palate. (Illustration courtesy of Aiden Farrow, copyright 2018). CL, cleft lip. 
FIG. 3. Clefts of the palate. This figure illustrates three presentations of a CP. (A) cleft of the soft palate, (B) cleft of the hard and soft palate, and (C) a wide U-shaped cleft, typical of PRS. (Illustration courtesy of Aiden Farrow, copyright 2018). CP, cleft palate; PRS, Pierre Robin sequence.

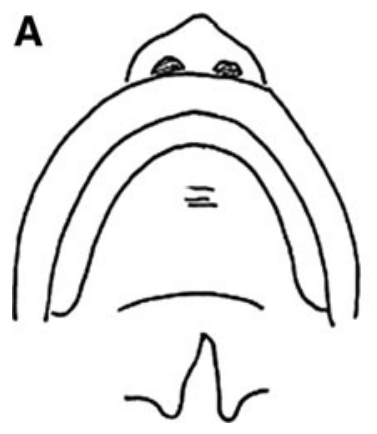

3. There is moderate evidence to suggest that infants with CL may be able to generate sufficient suction ${ }^{19}$ (level 4), and descriptive reports suggest that these infants are often able to breastfeed successfully ${ }^{36-38}$ (levels 4-5). There is moderate evidence that infants with CP or CLP have difficulty generating sufficient intraoral suction ${ }^{15}$ (level 2) and may have inefficient sucking patterns ${ }^{16}$ (level 3) compared with noncleft infants. Overall, infants with CP or CLP are observed to have lower success rates for breastfeeding than infants with CL or no cleft. This applies even after surgical repair ${ }^{39}$ (level 3). Nonetheless, breastfeeding attempts may still be beneficial for maintaining milk supply if a mother is also expressing breast milk. ${ }^{15,16}$ Breastfeeding may also provide comfort and bonding opportunities for infants and mothers, while allowing infants to experience feeding from the breast. ${ }^{40,41}$

4. Evidence suggests that breastfeeding can commence/ recommence immediately after CL repair ${ }^{3,4,42}$ (levels 2-3). Breastfeeding can commence/recommence 1 day after $\mathrm{CP}$ repair without complication to the

A
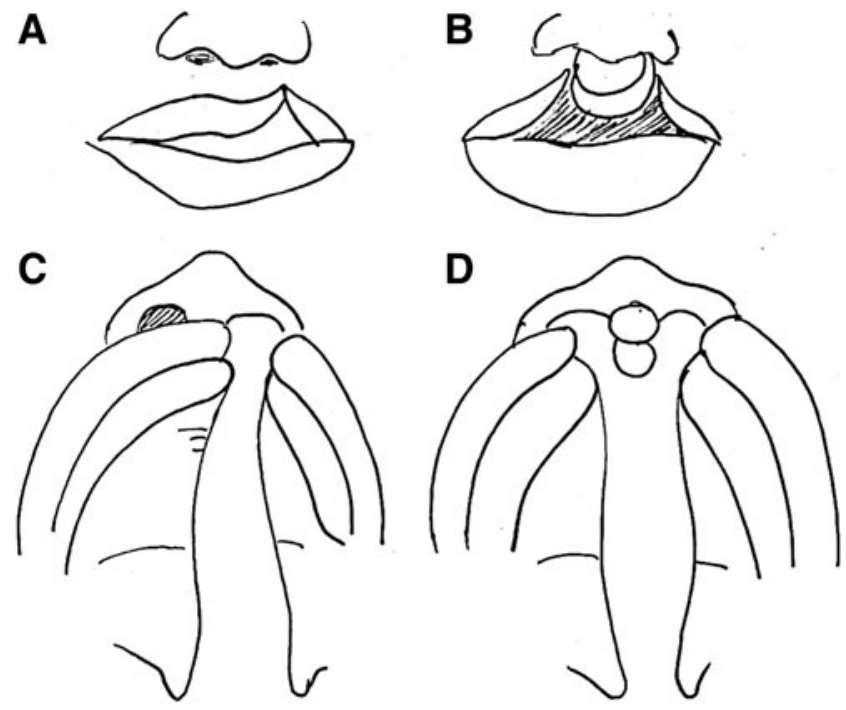

FIG. 4. Unilateral and bilateral CLP. This illustration shows (A) unilateral CL (left), (C) accompanying (A) unilateral CP (left), (B) bilateral complete cleft of the lip and gum with the columella present, and (D) accompanying (B) complete cleft of the palate. (Illustration courtesy of Aiden Farrow, copyright 2018). CLP, cleft lip and palate.
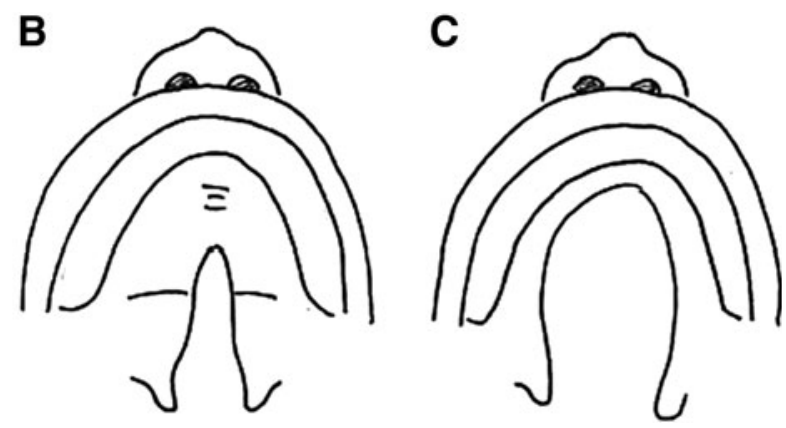

wound. ${ }^{4}$ In a survey of surgeons regarding postoperative care after palatoplasty, two-thirds of surgeons allowed mothers to breastfeed immediately after surgery ${ }^{43}$ (level 4). However, as cleft repairs do not occur immediately after birth, infants may require additional support to be taught how to breastfeed with their newly repaired clefts. Therefore, parents should be counseled that alternative means of feeding may still be required postsurgically to meet growth and nutritional goals. ${ }^{35}$ Personal and social supports are also important during this time. ${ }^{31,32}$

B. Provide timely assessment and support

1. Parental education and supports should be provided in a timely manner. Surveys have indicated that parents of a child with CL, CLP, or CP desire more instruction on feeding challenges as early as possible; this commences in the antenatal period and should be ongoing ${ }^{32}$ (level 4). Involving partners and other caregivers in the feeding process is also recommended. $^{31}$

2. Several studies have suggested that there are benefits from having access to a health professional who specializes in CL/P and breastfeeding, such as a clinical nurse specialist or lactation specialist (including International Board Certified Lactation Consultants [IBCLC]), during the newborn and later periods. Specialists can determine the feasibility of breastfeeding and advise about managing milk supply and expressing for supplemental feeds. Early advice is key, as mothers may be encouraged to initiate milk expression within the first few hours of birth. ${ }^{44}$ Specialists can also assist with suitable supportive techniques (outlined in the "Implement Strategies to Support Breastfeeding" section). ${ }^{31,33,45}$ It is important to consider the size and location of the infant's cleft, breast anatomy, the parent's wishes, and previous experience with breastfeeding.

3. Families may benefit from peer support around breastfeeding or breast milk feeding found through local support groups and associations, such as Wide Smiles, ${ }^{46}$ in addition to routine referral to breastfeeding support groups.

4. An infant's hydration and weight gain should be monitored while a feeding method is being established. If breast milk feeding alone is inadequate, supplemental feeding should be implemented or increased if indicated (see "ABM clinical protocol \#3: Hospital guidelines for the use of supplementary feedings in the healthy term breastfed neonate, 
revised $2017^{, 47}$ ). Infants with $\mathrm{CL} / \mathrm{P}$ may require supplemental feeds for adequate growth and nutrition $^{20,38}$ (level 4). Evidence from a single study demonstrated that additional maternal support by a clinical nurse specialist can both improve weight gain and facilitate early referral to appropriate services $^{48}$ (level 4).

5. When CL/P occurs as part of a syndrome/sequence, the potential for breastfeeding should be assessed on a case-by-case basis, taking into account any additional features of the syndrome that may impact breastfeeding success.

6. If a palatal prosthesis is used for orthopedic alignment before surgery, caution should be taken in advising parents to use such a device to facilitate breastfeeding. Rather, parents should be informed that the device likely will not significantly increase breastfeeding efficiency or effectiveness (levels 1-4). ${ }^{49,50}$

C. Implement strategies to support breastfeeding

1. Modified breastfeeding positions may increase the efficiency and effectiveness of breastfeeding. There are many recommendations about physical positioning of the infant to support breastfeeding. However, they are supported by weak evidence (clinical experience or expert opinion). Specific recommendations that require future evaluation include:

- For infants with CL.

- The infant should be held so that the CL is oriented toward the top of the breast ${ }^{50,51}$ (level 4). For example, an infant with a right CL may feed more efficiently in a crosscradle position at the right breast and a "football/twin style" position (i.e., the body

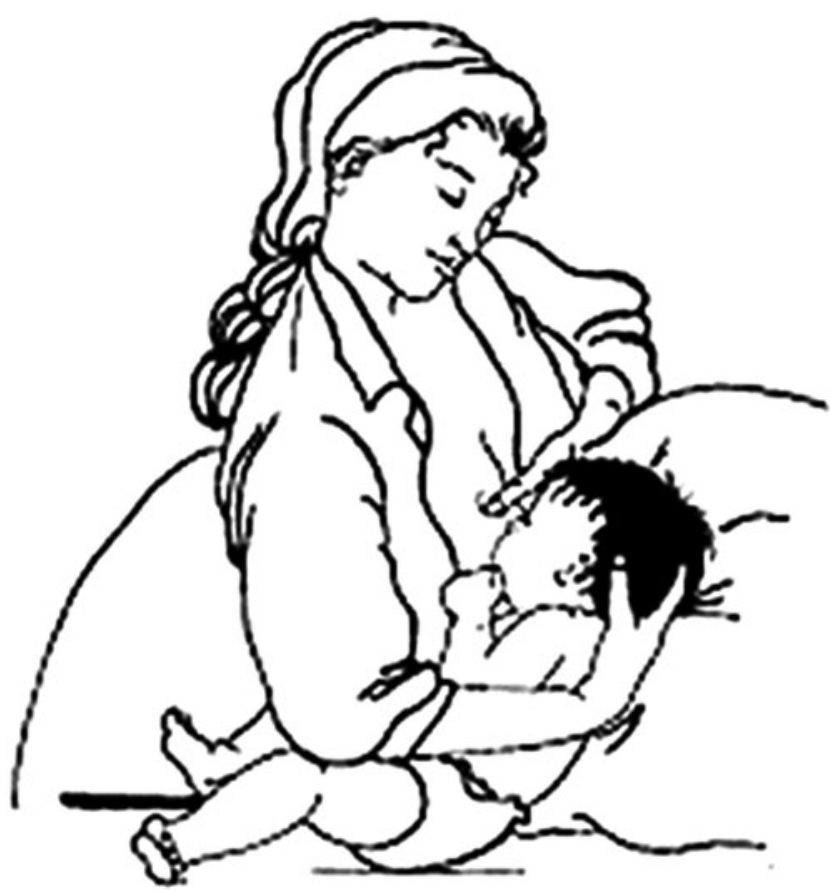

FIG. 5. "Football Hold" feeding position. This illustration shows the "Football Hold" breastfeeding position that may be used for infants with CL, CP, or CLP. (Illustration courtesy of Children's Minnesota Hospital). of the infant positioned alongside the mother, rather than across the mother's lap, with the infant's shoulders higher than his or her body) at the left breast (Fig. 5).

- For bilateral CL, a "face on" straddle position may be more effective than other breastfeeding positions ${ }^{51}$ (level 4 ).

- For infants with CP or CLP.

- Positioning should be semi-upright to reduce nasal regurgitation and flow of breast milk into the eustachian tubes (Fig. 6) ${ }^{51-55}$ (level 4).

O A "football/twin style" position may be more effective than a cross-cradle position ${ }^{54,55}$ (level 4).

2. In addition to modifying positioning of the infant, parents can implement the following strategies. These strategies are supported by similarly weak evidence (clinical experience or expert opinion):

- For infants with CL.

- The parent may occlude the CL with a thumb or finger ${ }^{51,52}$ and/or support the infant's cheeks to decrease the width of the cleft and increase closure around the nipple ${ }^{56}$ (level 4).

- For infants with CP or CLP.

- For infants with $\mathrm{CP}$, it may be useful to position the breast toward the "greater segment" of the palate. That is, the side of the palate that has the most intact bone. This may facilitate better generation of negative pressure and thus milk extraction, while preventing the nipple from being pushed into the cleft site ${ }^{57}$ (level 4).

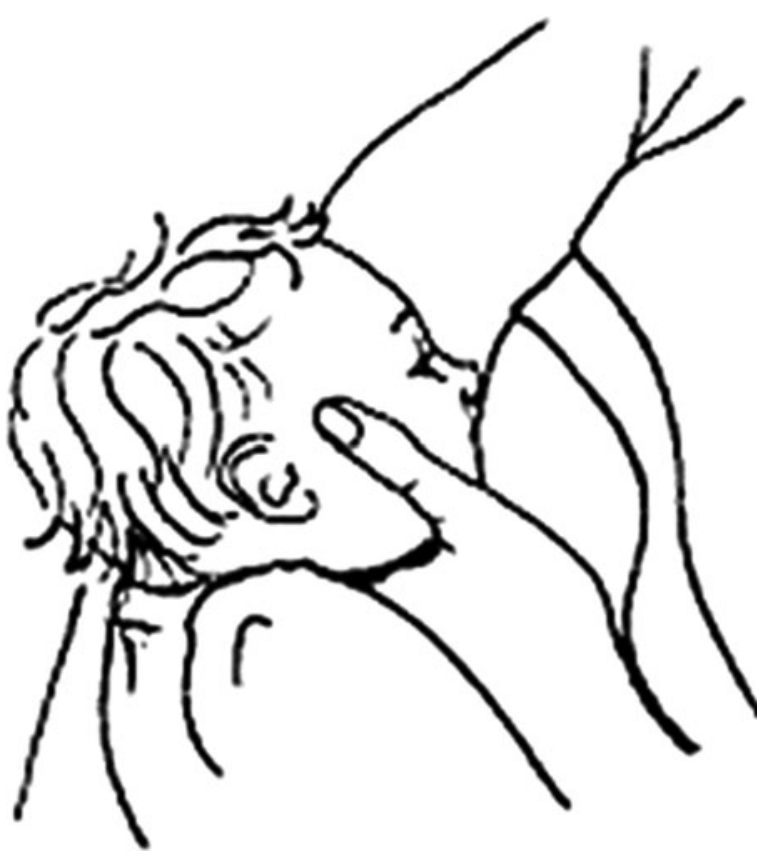

FIG. 6. Supporting the infant's chin during breastfeeding. This illustration demonstrates how a mother may use her free hand to support an infant's chin and/or breast to maintain a semi-upright position. This can help to stabilize the jaw during breastfeeding and ensure that the breast remains in the infant's mouth. (Illustration courtesy of Children's Minnesota Hospital). 
- If the cleft is large, some experts suggest that the breast be positioned downward to stop the nipple being pushed into the cleft ${ }^{51}$ (level 4).

- Some experts suggest supporting the infant's chin to stabilize the jaw during sucking ${ }^{52}$ an$\mathrm{d}$ /or supporting the breast so that it remains in the infant's mouth (Fig. 6) ${ }^{56,58}$ (level 4).

- Mothers may need to manually express breast milk into the baby's mouth to compensate for absent suction and compression and to stimulate the let-down reflex ${ }^{15}$ (level 4).

\section{Recommendations for future research}

The most pressing issue for health care professionals working with parents who wish to breastfeed their infants with $\mathrm{CL} / \mathrm{P}$ is the lack of evidence on which to base clinical recommendations. Well-designed data-driven investigations are imperative to generate high-level evidence and inform future guidelines. Future research is needed, covering the areas of feeding rates, management strategies, economic outcomes for breastfeeding infants with clefts, and health and developmental outcomes for infants with CL/P (e.g., communication, parent satisfaction, and rates of upper respiratory tract infections). Furthermore, investigators must clearly describe their sample of infants and intervention techniques so that the research outcomes can be generalized. Differentiation between cleft types and sizes is particularly important in this cohort.

\section{Acknowledgments}

We thank international reviewers, Dr. Sandra Massry, Dr. Makiko Ohyama, and Aiden Farrow, BSc, Cert PPH, IBCLC, for their valuable input toward the revision of this protocol. We extend our gratitude to Aiden Farrow and Children's Minnesota Hospital for permission to use their illustrations.

\section{References}

1. Allori AC, Mulliken JB, Meara JG, et al. Classification of cleft lip/palate: Then and now. Cleft Palate Craniofac $J$ 2017;54:175-188.

2. Fogh-Andersen P. Inheritance of Harelip and Cleft Palate: Contribution to the Elucidation of the Etiology of the Congenital Clefts of the Face. Copenhagen: Munksgaard, 1942.

3. de Ladeira PR, Alonso N. Protocols in cleft lip and palate treatment: Systematic review. Plast Surg Int 2012 2012: $1-9$.

4. Bessell A, Hooper L, Shaw WC, et al. Feeding interventions for growth and development in infants with cleft lip, cleft palate or cleft lip and palate. Cochrane Database Syst Rev 2011;CD003315.

5. Conway H, Wagner KJ. Incidence of clefts in New York City. Cleft Palate Craniofac J 1996;33:284-290.

6. WHO. Global Registry and Database on Craniofacial Anomalies: Report of a WHO Registry Meeting on Craniofacial Anomalies. Baru, Brazil: World Health Organization, Programme HG, 2001.

7. IPDTOC Working Group. Prevalence at birth of cleft lip with or without cleft palate: Data from the International Perinatal Database of Typical Oral Clefts (IPDTOC). Cleft Palate Craniofac J 2011;48:66-81.
8. Croen LA, Shaw GM, Wasserman CR, et al. Racial and ethnic variations in the prevalence of orofacial clefts in California, 1983-1992. Am J Med Genet 1998;79:42-47.

9. Mulliken JB. Repair of bilateral complete cleft lip and nasal deformity-State of the art. Cleft Palate Craniofac J 2000; 37:342-347.

10. Mossey PA, Modell B. Epidemiology of oral clefts 2012: An international perspective. Front Oral Biol 2012;16:1-18.

11. Brake SC, Fifer WP, Alfasi G, et al. The first nutritive sucking responses of premature newborns. Infant Behav Dev 1988;11:1-19.

12. Weber F, Woolridge MW, Baum JD. An ultrasonographic study of the organisation of sucking and swallowing by newborn infants. Dev Med Child Neurol 1986;28:19-24.

13. Reid J. Feeding Babies with Cleft Lip and/or Palate: An Overrated Problem or a Neglegted Aspect of Care? Melbourne: La Trobe University, 2004.

14. Reid J, Reilly S, Kilpatrick N. Sucking performance of babies with cleft conditions. Cleft Palate Craniofac J 2007; 44:312-320.

15. Masarei AG, Sell D, Habel A, et al. The nature of feeding in infants with unrepaired cleft lip and/or palate compared with healthy noncleft infants. Cleft Palate Craniofac $J$ 2007;44:321-328.

16. Mizuno K, Ueda A, Kani K, et al. Feeding behaviour of infants with cleft lip and palate. Acta Paediatr 2002;91: 1227-1232.

17. Mizuno K, Ueda A. Development of sucking behavior in infants who have not been fed for 2 months after birth. Pediatr Int 2001;43:251-255.

18. Choi BH, Kleinheinz J, Joos U, et al. Sucking efficiency of early orthopaedic plate and teats in infants with cleft lip and palate. Int J Oral Maxillofac Surg 1991;20:167-169.

19. Smedegaard L, Marxen D, Moes J, et al. Hospitalization, breast-milk feeding, and growth in infants with cleft palate and cleft lip and palate born in Denmark. Cleft Palate Craniofac J 2008;45:628-632.

20. Abbott MA. Cleft lip and palate. Pediatr Rev 2014;35:177181.

21. Kaye A, Thaete K, Snell A, et al. Initial nutritional assessment of infants with cleft lip and/or palate: Interventions and return to birth weight. Cleft Palate Craniofac $J$ 2017;54:127-136.

22. Gottschlich MM, Mayes T, Allgeier C, et al. A retrospective study identifying breast milk feeding disparities in infants with cleft palate. J Acad Nutr Diet 2018;11: 2154-2161.

23. Reid J. A review of feeding interventions for infants with cleft palate. Cleft Palate Craniofac J 2004;41:268-278.

24. Levels of Evidence. 2011. Available at https://www.cebm .net/2016/05/ocebm-levels-of-evidence (accessed March 22, 2019).

25. Paradise JL, Elster BA, Tan L. Evidence in infants with cleft palate that breast milk protects against otitis media. Pediatrics 1994;94:853-860.

26. Kuo CL, Tsao YH, Cheng HM, et al. Grommets for otitis media with effusion in children with cleft palate: A systematic review. Pediatrics 2014;134:983-994.

27. Garcez LW, Giugliani ER. Population-based study on the practice of breastfeeding in children born with cleft lip and palate. Cleft Palate Craniofac J 2005;42:687-693.

28. Victora CG, Bahl R, Barros AJD, et al. Breastfeeding in the 21st century: Epidemiology, mechanisms, and lifelong effect. Lancet 2016;387:475-490. 
29. Bernard JY, De Agostini M, Forhan A, et al. Breastfeeding duration and cognitive development at 2 and 3 years of age in the EDEN mother-child cohort. J Pediatr 2013;163:36-42.

30. Kramer MS, Kakuma R. Optimal duration of exclusive breastfeeding. Cochrane Database Syst Rev 2012;8:1-139.

31. Lindberg N, Berglund AL. Mothers' experiences of feeding babies born with cleft lip and palate. Scand J Caring Sci 2014;28:66-73.

32. Owens J. Parents' experiences of feeding a baby with cleft lip and palate. Br J Midwifery 2008;16:778-784.

33. Alperovich M, Frey JD, Shetye PR, et al. Breast milk feeding rates in patients with cleft lip and palate at a north american craniofacial center. Cleft Palate Craniofac J 2017;54:334-337.

34. Kaye A, Cattaneo C, Huff HM, et al. A pilot study of mothers' breastfeeding experiences in infants with cleft lip and/or palate. Adv Neonatal Care 2018;1-11.

35. McGuire E. Cleft lip and palates and breastfeeding. Breastfeed Rev 2017;25:17-23.

36. Merrow JM. Feeding management in infants with craniofacial anomalies. Facial Plast Surg Clin North Am 2016;24: 437-444.

37. Goyal A, Jena AK, Kaur M. Nature of feeding practices among children with cleft lip and palate. J Indian Soc Pedod Prev Dent 2012;30:47-50.

38. Gil-Da-Silva-Lopes VL, Xavier AC, Klein-Antunes D, et al. Feeding infants with cleft lip and/or palate in Brazil: Suggestions to improve health policy and research. Cleft Palate Craniofac J 2013;50:577-590.

39. Burianova I, Kulihova K, Vitkova V, et al. Breastfeeding after early repair of cleft lip in newborns with cleft lip or cleft lip and palate in a baby-friendly designated hospital. J Hum Lact 2017;33:504-508.

40. Dieterich CM, Felice JP, O'Sullivan E, et al. Breastfeeding and health outcomes for the mother-infant dyad. Pediatr Clin North Am 2013;60:31-48.

41. Liu J, Leung P, Yang A. Breastfeeding and active bonding protects against children's internalizing behavior problems. Nutrients 2013;6:76-89.

42. Lazarou S. Comparison of neonatal cleft lip repair to standard time repair done by same surgeon. Cleft Palate Craniofac J 2016;53:e107.

43. Darzi MA, Chowdri NA, Bhat AN. Breast feeding or spoon feeding after cleft lip repair: A prospective, randomised study. Br J Plast Surg 1996;49:24-26.

44. Burca ND, Gephart SM, Miller C. A nurse's guide to promoting breast milk nutrition in infants with cleft lip and/or palate. Adv Neonatal Care 2016;16:345-346.

45. Chuacharoen R, Ritthagol W, Hunsrisakhun J, et al. Felt needs of parents who have a 0- to 3-month-old child with a cleft lip and palate. Cleft Palate Craniofac J 2009;46:252-257.

46. Wide Smiles. Wide Smiles Website 2018. Available at http://widesmiles.org. Last accessed 22 Mar 2019.

47. Kellams A, Harrel C, Omage S, et al. ABM clinical protocol \#3: Supplementary feeding in healthy term breastfed neonate, revised 2017. Breastfeed Med 2017;12:1-8.

48. Danner SC. Breastfeeding the infant with a cleft defect. NAACOGS Clin Issu Perinat Womens Health Nurs 1992;3: 634-639.

49. Prahl C, Kuijpers-Jagtman AM, Van 't Hof MA, et al. Infant orthopedics in UCLP: Effect on feeding, weight, and length: A randomized clinical trial (Dutchcleft). Cleft $\mathrm{Pa}$ late Craniofac J 2005;42:171-177.
50. Cohen M, Marschall MA, Schafer ME. Immediate unrestricted feeding of infants following cleft lip and palate repair. J Craniofac Surg 1992;3:30-32.

51. Helsing E, King FS. Breastfeeding under special conditions. Nurs J India 1985;76:46-47.

52. Bardach J, Morris HL. Multidisciplinary Management of Cleft Lip and Palate. Philadelphia: WB Saunders Co, 1990.

53. Dunning Y. Child nutrition. Feeding babies with cleft lip and palate. Nurs Times 1986;82:46-47.

54. McKinstry RE. Presurgical management of cleft lip and palate patients. In: Cleft Palate Dentistry, McKinstry RE, ed. Arlington: ABI Professional Publications, 1998, pp. 33-66.

55. Burca ND, Gephart SM, Miller C, et al. Promoting breast milk nutrition in infants with cleft lip and/or palate. $A d v$ Neonatal Care 2016;16:337-344.

56. Arvedson JC. Feeding with craniofacial anomalies. In: Pediatric Swallowing and Feeding: Assessment and Management, 2nd ed., Arvedson JC, Brodsky LB, eds. Albany, NY: Singular Publishing Group, 2002, pp. 527-561.

57. Glass RP, Wolf LS. Feeding management of infants with cleft lip and palate and micrognathia. Infants Young Child 1999;12:70-81.

58. Masarei AG. An Investigation of the Effects of Pre-surgical Orthopaedics on Feeding in Infants with Cleft Lip and/or Palate. London: University College, 2003.

\section{Jessica O. Boyce, PhD, lead author Sheena Reilly, PhD Jemma Skeat, PhD Petrea Cahir, M (Sp Path)}

Protocol Committee Members 2019: Michal Young, MD, FABM, Chairperson

Larry Noble, MD, FABM, Translations Chairperson Sarah Reece-Stremtan, Secretary

Melissa Bartick, MD, FABM

Sarah Calhoun, MD

Sarah Dodd, MD

Megan Elliott-Rudder, $M D$

Laura Rachael Kair, MD, FABM

Susan Lappin, MD

Ilse Larson, $M D$

Ruth A. Lawrence, MD, FABM

Yvonne Lefort, MD, FABM

Kathleen A. Marinelli, MD, FABM

Nicole Marshall, MD, MCR

Katrina Mitchell, MD, FABM

C. Murak, $M D$

Eliza Myers, $M D$

Adora Okogbule-Wonodi, MD

Casey Rosen-Carole, MD, MPH, MSEd

Susan Rothenberg, MD, FABM

Tricia Schmidt, $M D$

Tomoko Seo, MD, FABM

Natasha Sriraman, MD

Elizabeth K. Stehel, MD

Rose St. Fleur, MD

Nancy Wight, MD

Lori Winter, MD

For correspondence: abm@bfmed.org 


\section{Appendix}

\section{Appendix A1. Frequently Asked Questions}

Breastfeeding infants with cleft lip $(C L)$, cleft palate $(C P)$, or $C L$ and $C P(C L P)$

Except where noted, the literature reviewed relates to infants with nonsyndromic CL/P.

\section{Can infants with CL breastfeed successfully?}

There was no strong evidence with regard to breastfeeding infants with CL. There was moderate (levels 2-3) evidence that babies with CL can create suction during feeding. ${ }^{\mathrm{A} 1, \mathrm{~A} 2}$ Descriptive studies (level 4) have demonstrated successful breastfeeding at rates approaching the general population. ${ }^{\mathrm{A} 3}$ Expert opinion (level 4) suggested that infants with CL may find breastfeeding relatively easy compared with bottle feeding because the breast tissue molds to the cleft and occludes the defect more successfully than an artificial nipple. ${ }^{\mathrm{A} 4, \mathrm{~A} 5}$ Expert opinion also suggested that modifications to positioning can facilitate breastfeeding for these infants. ${ }^{\mathrm{A} 6-\mathrm{A} 8}$

2. Can infants with CP breastfeed successfully?

There was no strong evidence with regard to breastfeeding infants with CP. There was moderate (levels 2-3) evidence that infants with $\mathrm{CP}$ do not create adequate suction when bottle feeding. ${ }^{\mathrm{A} 1, \mathrm{~A} 2}$ Some infants with clefts of the soft palate only may be able to create suction, although this is not usually the case. ${ }^{\mathrm{A} 1, \mathrm{~A} 9}$ Descriptive studies and a systematic review indicated that breastfeeding success for infants with $\mathrm{CP}$ was much lower than for infants with CL. ${ }^{\text {A7,A10-A16 }}$ There was weak evidence (level 4) to suggest that partial breastfeeding (with supplementation) can be achieved and that the size and location of the cleft are determining factors for breastfeeding success. ${ }^{\mathrm{A} 5, \mathrm{~A} 17, \mathrm{~A} 18}$ As with infants with CL, supportive and compensatory strategies are reported to increase breastfeeding success (level 4). ${ }^{\mathrm{A} 6, \mathrm{~A} 7, \mathrm{~A} 17, \mathrm{~A} 18}$

3. Can infants with cleft lip and palate (CLP) breastfeed successfully?

There was no strong evidence with regard to breastfeeding infants with CLP. There was moderate evidence that infants with CLP are unable to create suction when fed using a bottle $\mathrm{A}^{\mathrm{A}, \mathrm{A} 2, \mathrm{~A} 9}$ (levels 2-3) and moderate to weak evidence that infants with CLP are sometimes able to breastfeed successfully. ${ }^{\text {A14 }}$ Descriptive studies suggested breastfeeding success rates ranging from $0 \%$ to $40 \%$. $^{\mathrm{A}, \mathrm{A} 13, \mathrm{~A} 19}$ Supportive and compensatory strategies recommended by experts may increase breastfeeding success ${ }^{\mathrm{A} 6, \mathrm{~A} 8, \mathrm{~A} 17, \mathrm{~A} 18, \mathrm{~A} 20, \mathrm{~A} 21}$ (level 4). There was weak evidence that suggests breastfeeding rates for infants with CLP decrease sharply after 6 months of age. ${ }^{\text {A20 }}$

4. Is there evidence to guide assessment and management of breastfeeding in infants with CL/P?

There is moderate evidence that lactation education is important to facilitate successful feeding in infants with $\mathrm{CL} / \mathrm{P}^{\mathrm{A} 4, \mathrm{~A} 22-\mathrm{A} 25}$ (levels $3-4$ ). This support should be provided by professionals with knowledge and expertise specific to feeding infants with $\mathrm{CL} / \mathrm{P}$. The remaining evidence is weak and focuses on (a) areas for monitoring, (b) recommendations for supplementation, (c) compensatory and supportive strategies, and (d) the importance of counseling to encourage breast milk feeding ${ }^{\mathrm{A} 23}$ (level 4).
5. Is there evidence that palatal obturators facilitate breastfeeding success with infants with CLP or CP?

Breastfeeding outcomes may be affected by the use of feeding plates (which obturate some of the cleft and attempt to "normalize" the oral cavity for feeding) ${ }^{\mathrm{A} 26}$ or presurgical orthopedic devices (prostheses used to reposition the cleft segments before surgery). These are collectively referred to as "obturators" for this report. There was strong evidence that obturators do not facilitate feeding or weight gain in breastfed babies with CLP ${ }^{\mathrm{A} 27}$ and that they do not improve the infant's ability to efficiently bottle feed ${ }^{\mathrm{A} 6}$ (levels 1-2). There was moderate evidence that obturators do not facilitate suction during bottle feeding ${ }^{\mathrm{A} 28}$ (level 3). This is because obturators do not enable complete closure of the soft palate against the walls of the throat during feeding. Contradictory evidence exists, supporting the use of obturators to facilitate breastfeeding in infants with CP or CLP, but it is from much weaker sources ${ }^{\mathrm{A} 4, \mathrm{~A} 21, \mathrm{~A} 29}$ (levels 3-4).

6 . Is there evidence for additional benefits of breastfeeding for infants with $\mathrm{CL} / \mathrm{P}$ compared with the noncleft population?

Several moderate to weak studies (levels 3-4) exist, with the majority of evidence representing expert opinion (level 4). It is well accepted that breastfeeding and breast milk feeding convey positive benefits to both mother and infant. With regard to infants with $\mathrm{CP}$, there was moderate to weak evidence that feeding with breast milk protects against otitis media. ${ }^{\mathrm{A} 4, \mathrm{~A} 30}$ These infants are more prone to otitis media than the general population because of the abnormal soft palate musculature. ${ }^{\mathrm{A} 0}$ There was moderate to weak evidence that breast milk can promote intellectual development and academic outcomes in individuals with clefts. ${ }^{\text {A31 }}$ In addition, experts have suggested that breastfeeding facilitates the development of oral facial musculature, ${ }^{\mathrm{A} 21}$ speech, ${ }^{\mathrm{A} 18, \mathrm{~A} 21}$ bonding, ${ }^{\mathrm{A} 18}$ and pacifying infants after surgery. ${ }^{\mathrm{A} 4, \mathrm{~A} 21}$

7. Is there evidence to indicate when it is safe to commence/recommence breastfeeding after lip or palate surgery?

CL repair (cheiloplasty) is generally carried out within a few months of birth, and CP repair (palatoplasty) often takes place between 6 and 12 months of age. ${ }^{\mathrm{A} 32}$ There are several studies that have yielded strong evidence to inform this area. There was moderate to strong evidence (levels 2-3) that it is safe to commence/recommence breastfeeding immediately after CL repair ${ }^{\mathrm{A} 33, \mathrm{~A} 34}$ (levels $2-3$ ), and there was moderate evidence for initiating breastfeeding 1 day after $\mathrm{CP}$ repair $^{\mathrm{A} 34}$ (level 3). There was strong evidence that breastfeeding immediately after surgery is more effective for weight gain than spoon feeding, with associated lower hospital costs ${ }^{\mathrm{A} 34}$ (levels 1-2). Contradictory evidence exists, but it is from weaker sources and is divided as to recommendations $^{\mathrm{A} 8, \mathrm{~A} 35}$ (level 4).

8. Is there evidence to indicate whether infants with $\mathrm{CP}$ as part of a syndrome/sequence can breastfeed?

There are $>340$ syndromes in which CL/P appears. It is beyond the scope of this protocol to review and make 
recommendations for them all in detail. However, some key data are presented to guide breastfeeding practice. Moderate to weak evidence suggested that, as well as the cleft, additional oral facial anomalies associated with these syndromes (e.g., hypotonia, micrognathia, and glossoptosis) impact feeding success. ${ }^{\text {13, A15,A17,A36 }}$ It is important to examine the influence of additional structural and functional anomalies on feeding and design individualized treatment accordingly.

\section{Appendix References}

A1. Masarei AG, Sell D, Habel A, et al. The nature of feeding in infants with unrepaired cleft lip and/or palate compared with healthy noncleft infants. Cleft Palate Craniofac $J$ 2007;44:321-328.

A2. Smedegaard L, Marxen D, Moes J, et al. Hospitalization, breast-milk feeding, and growth in infants with cleft palate and cleft lip and palate born in Denmark. Cleft Palate Craniofac J 2008;45:628-632.

A3. Garcez LW, Giugliani ER. Population-based study on the practice of breastfeeding in children born with cleft lip and palate. Cleft Palate Craniofac J 2005;42:687-693.

A4. Paradise JL, Elster BA, Tan L. Evidence in infants with cleft palate that breast milk protects against otitis media. Pediatrics 1994;94:853-860.

A5. Gopinath VK, Muda WA. Assessment of growth and feeding practices in children with cleft lip and palate. Southeast Asian J Trop Med Public Health 2005;36:254-258.

A6. Cohen M, Marschall MA, Schafer ME. Immediate unrestricted feeding of infants following cleft lip and palate repair. J Craniofac Surg 1992;3:30-32.

A7. Helsing E, King FS. Breastfeeding under special conditions. Nurs J India 1985;76:46-47.

A8. Bardach J, Morris HL. Multidisciplinary Management of Cleft Lip and Palate. Philadelphia: WB Saunders Co., 1990.

A9. Reid J, Reilly S, Kilpatrick N, eds. Breastmilk consumption in babies with clefts. In: 63rd Annual meeting of the American Cleft Palate-Craniofacial Association, Vancouver, 2006.

A10. Kaye A, Thaete K, Snell A, et al. Initial nutritional assessment of infants with cleft lip and/or palate: Interventions and return to birth weight. Cleft Palate Craniofac J 2017;54:127-136.

A11. Gottschlich MM, Mayes T, Allgeier C, et al. A retrospective study identifying breast milk feeding disparities in infants with cleft palate. J Acad Nutr Diet 2018;11:2154-2161.

A12. Gil-Da-Silva-Lopes VL, Xavier AC, Klein-Antunes D, et al. Feeding infants with cleft lip and/or palate in Brazil: Suggestions to improve health policy and research. Cleft Palate Craniofac J 2013;50:577-590.

A13. Burianova I, Kulihova K, Vitkova V, et al. Breastfeeding after early repair of cleft lip in newborns with cleft lip or cleft lip and palate in a baby-friendly designated hospital. J Hum Lact 2017;33:504-508.

A14. Chuacharoen R, Ritthagol W, Hunsrisakhun J, et al. Felt needs of parents who have a 0- to 3-month-old child with a cleft lip and palate. Cleft Palate Craniofac J 2009;46: 252-257.

A15. de Vries IA, Breugem CC, van der Heul AM, et al. Prevalence of feeding disorders in children with cleft palate only: A retrospective study. Clin Oral Investig 2014;18: 1507-1515.
A16. Galvao D, Lopes A, Martins C, et al. Breastfeeding children with cleft LIP and/or palate. Atencion Primaria 2014;46 (Supplement 5):26.

A17. Dunning Y. Child nutrition. Feeding babies with cleft lip and palate. Nurs Times 1986;82:46-47.

A18. McKinstry RE. Presurgical management of cleft lip and palate patients. In: Cleft Palate Dentistry, McKinstry RE, ed. Arlington: ABI Professional Publications, 1998, pp. 33-66.

A19. Aniansson G, Svensson H, Becker M, et al. Otitis media and feeding with breast milk of children with cleft palate. Scand J Plast Reconstr Surg Hand Surg 2002;36:9-15.

A20. Goyal A, Jena AK, Kaur M. Nature of feeding practices among children with cleft lip and palate. J Indian Soc Pedod Prev Dent 2012;30:47-50.

A21. Danner SC. Breastfeeding the infant with a cleft defect. NAACOGS Clin Issu Perinat Womens Health Nurs 1992; 3:634-639.

A22. Lindberg N, Berglund AL. Mothers' experiences of feeding babies born with cleft lip and palate. Scand $J$ Caring Sci 2014;28:66-73.

A23. Alperovich M, Frey JD, Shetye PR, et al. Breast milk feeding rates in patients with cleft lip and palate at a north american craniofacial center. Cleft Palate Craniofac $J$ 2017;54:334-337.

A24. Kaye A, Cattaneo C, Huff HM, et al. A pilot study of mothers' breastfeeding experiences in infants with cleft lip and/or palate. Adv Neonatal Care 2018;1-11.

A25. McGuire E. Cleft lip and palates and breastfeeding. Breastfeed Rev 2017;25:17-23.

A26. Masarei AG. An Investigation of the Effects of Presurgical Orthopaedics on Feeding in Infants with Cleft Lip and/or Palate. London: University College, 2003.

A27. Prahl C, Kuijpers-Jagtman AM, Van 't Hof MA, et al. Infant orthopedics in UCLP: Effect on feeding, weight, and length: A randomized clinical trial (Dutchcleft). Cleft Palate Craniofac J 2005;42:171-177.

A28. Choi BH, Kleinheinz J, Joos U, et al. Sucking efficiency of early orthopaedic plate and teats in infants with cleft lip and palate. Int J Oral Maxillofac Surg 1991;20:167-169.

A29. Goyal M, Chopra R, Bansal K, et al. Role of obturators and other feeding interventions in patients with cleft lip and palate: A review. Eur Arch Paediatr Dent 2014;15:1-9.

A30. Erkkila AT, Isotalo E, Pulkkinen J, et al. Association between school performance, breast milk intake and fatty acid profile of serum lipids in ten-year-old cleft children. J Craniofac Surg 2005;16:764-769.

A31. World Health Organization Health. Health factors which may interfere with breast-feeding. Bull World Health Organ 1989;67 Suppl:41-54.

A32. Abbott MA. Cleft lip and palate. Pediatr Rev 2014;35: 177-181.

A33. de Ladeira PR, Alonso N. Protocols in cleft lip and palate treatment: Systematic review. Plast Surg Int 2012 2012:1-9.

A34. Bessell A, Hooper L, Shaw WC, et al. Feeding interventions for growth and development in infants with cleft lip, cleft palate or cleft lip and palate. Cochrane Database Syst Rev 2011;Cd003315.

A35. Arvedson JC. Feeding with craniofacial anomalies. In: Pediatric Swallowing and Feeding: Assessment and Management, 2nd ed., Arvedson JC, Brodsky LB, eds. Albany, NY: Singular Publishing Group, 2002, pp. 527-561.

A36. Pandya AN, Boorman JG. Failure to thrive in babies with cleft lip and palate. Br J Plast Surg 2001;54:471475. 